Case Report

\title{
Hypereosinophilia with Gastrointestinal Involvement: A Case Report
}

Mauro Turrin ${ }^{1, *}$, Barbara Mariotti ${ }^{2}$, Isabella Schiavon ${ }^{2}$, Serena Battista ${ }^{3}$

1. Former Department of Internal Medicine, Ospedali Riuniti Padova Sud, "Madre Teresa di Calcutta", Monselice (Padova), Italy; E-Mail: m.turrin@libero.it

2. Department of Internal Medicine $1^{\wedge}$, Azienda Sanitaria Universitaria Integrata, Udine, Italy; EMails: barbara.mariotti@asuiud.sanita.fvg.it; isabella.schiavon@asuiud.sanita.fvg.it

3. Pathology Department, Azienda Sanitaria Universitaria Integrata, Udine, Italy; E-Mail: serena.battista@asuiud.sanita.fvg.it

* Correspondence: Mauro Turrin; E-Mail: m.turrin@libero.it

\section{ORCID ID}

Mauro Turrin; https://orcid.org/0000-0003-2100-2104

Barbara Mariotti; https://orcid.org/0000-0001-6900-8236

Isabella Schiavon; https://orcid.org/0000-0002-3399-932X

Serena Battista; https://orcid.org/0000-0002-8191-0131

Academic Editor: Tatsuo Kanda

OBM Hepatology and Gastroenterology

2019, volume 3 , issue 4

doi:10.21926/obm.hg.1904040
Received: September 29, 2019

Accepted: November 14, 2019

Published: November 22, 2019

\begin{abstract}
Hypereosinophilic syndrome is defined by an absolute blood eosinophil count of more than 1500 cells/ $\mu \mathrm{L}$ for more than one month and multiorgan system infiltration by eosinophils.

Eosinophilic colitis is an exceptionally rare inflammatory condition in which eosinophils infiltrate the colon. It is the rarest among an array of eosinophilic gastrointestinal disorders. We describe the case of an adult male patient with chronic eosinophilia for almost 25 years. During this period, he suffered from repeated episodes of abdominal colic that were caused by acute appendicitis with peritonitis, enterocolitis, and pancreatitis. All the episodes were associated with a marked increase in blood eosinophils but without IgE modification.
\end{abstract}

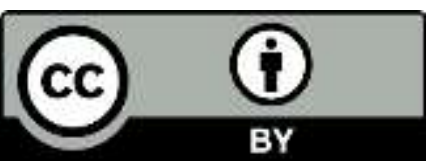

(C) 2019 by the author. This is an open access article distributed under the conditions of the Creative Commons by Attribution License, which permits unrestricted use, distribution, and reproduction in any medium or format, provided the original work is correctly cited. 
Malignant transformation of hypereosinophilia was not detected. Oral cortisone treatment was administered only for short periods of time.

\section{Keywords}

Eosinophils; hypereosinophilia; hypereosinophilic syndrome; eosinophilic colitis; eosinophilic pancreatitis

\section{Introduction}

Hypereosinophilic syndrome (HES) is defined by an absolute eosinophil count (AEC) exceeding 1500 cells/ $\mu \mathrm{L}$ at least twice per month for more than one month, and the evidence of eosinophiliaassociated organ impairment [1-3] (Table 1).

Table 1 Summary of ICOG definitions and diagnostic criteria of Eosinophilic Disorders. Modified from Kahn [4] and from Leru [5].

\begin{tabular}{|c|c|c|}
\hline Terminology & \multicolumn{2}{|c|}{ Definition and criteria } \\
\hline \multirow{8}{*}{ Blood eosinophilia } & \multicolumn{2}{|c|}{ Eosinophils $\left(\right.$ AEC) $>0.5 \times 10^{\wedge} 9 / \mathrm{L}$ in blood } \\
\hline & \multicolumn{2}{|c|}{$\begin{array}{l}\text { Normal value eosinophils: \% eosinophils in the peripheral } \\
\text { blood: } 3 \%-5 \%\end{array}$} \\
\hline & \multicolumn{2}{|c|}{ and/or AEC: $350-500 / \mu \mathrm{L}$} \\
\hline & \multicolumn{2}{|c|}{ (AEC: peripheral absolute eosinophils count) } \\
\hline & \multicolumn{2}{|c|}{ Classification of the severity of eosinophilia } \\
\hline & - Mild & AEC: upper limit of normal to $1500 / \mu \mathrm{L}$ \\
\hline & - Moderate & AEC: $1500-5000 / \mu \mathrm{L}$ \\
\hline & - Severe & AEC: $>5000 / \mu \mathrm{L}$ \\
\hline Hypereosinophilia (HE) & \multicolumn{2}{|c|}{$\begin{array}{l}\text { Eosinophils }>1.5 \times 10^{\wedge} 9 / \mathrm{L} \text { in blood on two examinations (interval } \\
>1 \text { month) and/or tissue } \mathrm{HE} \text { defined by the following: } \\
\text { 1. Percentage of eosinophils in bone marrow section exceeds } \\
20 \% \text { of all nucleated cells and/or } \\
\text { 2. Extensive tissue infiltration by eosinophils based on } \\
\text { pathologist report and/or } \\
\text { 3. Marked deposition of eosinophil granule proteins (in the } \\
\text { absence or presence of major tissue infiltration by eosinophils) }\end{array}$} \\
\hline
\end{tabular}




\begin{tabular}{|c|c|}
\hline Secondary (reactive) HE & $\begin{array}{l}\text { Clinical and laboratory evidence for causes of HE: } \\
\text { 1. Common allergic, reactive or immunologic conditions } \\
\text { 2. Hematopoietic neoplasms } \\
\text { 3. Non-hematopoietic neoplasms (paraneoplastic HE) } \\
\text { 4. Rare conditions associated with HE }\end{array}$ \\
\hline $\begin{array}{l}\text { Hypereosinophilic syndrome } \\
\text { (HES) }\end{array}$ & $\begin{array}{l}\text { 1. Criteria for peripheral blood HE fulfilled and } \\
\text { 2. Organ damage and/or dysfunction attributable to tissue HE } \\
\text { and } \\
\text { 3. Exclusion of secondary (reactive) HE as a major reason for } \\
\text { organ damage }\end{array}$ \\
\hline $\begin{array}{l}\text { HE of undetermined } \\
\text { significance (HEUS) }\end{array}$ & $\begin{array}{l}\text { 1. Criteria for peripheral blood HE fulfilled and } \\
\text { 2. No clinical symptoms and/or proof of organ dysfunction }\end{array}$ \\
\hline Overlap HE syndromes & Criteria for HES and EGPA (ANCA-negative subtype) \\
\hline Associated HE disorders & $\begin{array}{l}\text { 1. Criteria of HE fulfilled and } \\
\text { 2. Single-organ disease or Secondary (reactive) HE }\end{array}$ \\
\hline
\end{tabular}

ANCA: Antineutrophil cytoplasm antibody, EGPA: Eosinophil granulomatosis with polyangiitis, ICOG: International working group on eosinophil disorders

Eosinophilic gastrointestinal disorders (EGIDs) represent a rare, heterogeneous group of diseases (eosinophilic esophagitis, eosinophilic gastroenteritis, eosinophilic ileocolitis, and eosinophilic colitis) that are characterized by gastrointestinal symptoms, increased eosinophils in the intestinal parietal wall, and peripheral blood eosinophilia in $80 \%-90 \%$ of patients, which are often unexplained [6-9].

The clinical manifestations of EGIDs vary depending on the site of the affected GI tract and the extent of involvement and include abdominal pain, nausea, vomiting, early satiety, diarrhea, weight loss with protein-losing enteropathy, rectal bleeding, or bloating. The clinical management of EGIDs is difficult owing to their enigmatic nature and unknown etiology.

Primary eosinophilic colitis $(\mathrm{EOC})$ is the rarest entity in the spectrum of EGIDs. It has a bimodal age distribution, as it affects infants and young adults (it has even been reported in patients up to 89 years of age [10]), and has no gender preference.

Owing to its nonspecific symptoms with relapsing-remitting course and lack of distinctive clinical signs, the diagnosis of EOC in the absence of known causes such as tissue eosinophilia (parasitic infections, inflammatory bowel diseases, food or drug allergies, various connective tissue disorders, malignancy, and hypereosinophilic syndrome) is made by the histological examination of colonic biopsy material. Its only characteristic feature is an intense eosinophilic infiltration in the colon, that can be segmental or diffuse. The overall prevalence is $2-3 / 100,000$ persons $[7,11]$. 
Eosinophilic pancreatitis (EP), also a highly rare disease, is considered to be a variant of autoimmune pancreatitis. In this, the pancreatic CT scan may either be normal, present dilatation of the pancreatic duct, or frequently manifest a pseudocyst or pseudo-tumoral form [12-14].

\section{Why do We Describe this Case?}

Descriptions of hypereosinophilia associated with pancreatitis and with colitis are rare. Generally, clinical manifestations of eosinophilic gastrointestinal disorders vary and their etiology is unknown. Therefore, physicians should be aware of this heterogeneous group of diseases in order to avoid misdiagnosis.

\section{Case Report}

In 2016, we described the clinical case of a 55-year-old Caucasian patient who was under our observation for acute pancreatitis [15].

His clinical history showed the occurrence of asthma in early childhood and Gilbert's syndrome. He also showed a history of eosinophilia with peaks of up to $4.38 \times 10^{3} / \mu \mathrm{L}$ eosinophils (with total $\operatorname{lgE}=122 \mathrm{KU} / \mathrm{L}, \mathrm{nv}<100 \mathrm{KU} / \mathrm{L}$ ), since at least the year 1995 . None of his relatives were affected by eosinophilia. He did not have any allergies. He was also affected by hypertension, for which he was treated with losartan + hydrochlorothiazide. He had discontinued the habit of smoking 11 years before. He frequently ate cheese and cold cuts, drank at least $1 / 2$ liter of wine and 1-2 servings of gin and tonic in the weekend, and 6-8 cups of coffee and 4-5 cups of green tea every day. At the age of 38 years, he underwent appendectomy for acute appendicitis with serous peritonitis and an eosinophil count of $2.95 \times 10^{3} / \mu \mathrm{L}$. There was evidence of ascitic/peritoneal fluid, and the microscopic examination showed the presence of some lymphocytes, some neutrophil polymorphonuclear leukocytes, numerous red blood cells, no microorganisms, and few colonies of enterococci. The iliac crest biopsy revealed a myeloid series with increased eosinophilic share. Esophagogastroduodenoscopy (EGD) showed chronic superficial gastritis in the quiescent phase, but the test for Helicobacter pylori was negative.

In the year 2000 , due to abdominal pain and persistent eosinophilia $\left(2.34 \times 10^{3} / \mu \mathrm{L}\right.$, total and specific IgE normal), he repeated the EGD, which revealed fragments of gastric mucosa that were sometimes congested with an overall picture of chronic superficial gastritis in the slightly active phase; fragments of duodenal mucosa with images of congestion; and mild chronic inflammation.

The colonoscopy was negative. Biopsy of the bone marrow revealed moderate hyperplasia of the granulocytic line with an increase in the eosinophilic component at the level of promyelocytes and myelocytes. Antinuclear antibodies (ANA) and antineutrophil cytoplasm antibodies (ANCA) were negative.

He was then treated with prednisone for two years. In 2002, he performed tests due to recurrent episodes of abdominal pain. The tests initially showed a high eosinophil count, which lowered following short-term cortisone therapy. Since then, he had not performed any checks. In 2015, the patient first came to our observation with the complaint of intense epimesogastric pain radiated to back and associated with nausea. 
Table 2 Results of the laboratory tests (January 2015: first observation).

\begin{tabular}{|c|c|c|}
\hline Parameters & Detected Levels & Normal Range \\
\hline Lipase (U/L) & 2442 & $<67$ \\
\hline Pancreatic amylase (IU/L) & 552 & $<53$ \\
\hline CRP (mg/L) & 4,67 & $<5$ \\
\hline Eosinophils (×10^9/L) & 6.05 (43\% of leucocytes) & $<0.80$ \\
\hline IgE total (KU/L) & 49.6 & $0-87$ \\
\hline$\gamma G T(U / L)$ & 102 & $<55$ \\
\hline AST (U/L) & 105 & $<35$ \\
\hline $\operatorname{ALT}(U / L)$ & 78 & $<45$ \\
\hline ALP (U/L) & 116 & $30-120$ \\
\hline Total cholesterol (mg/dL) & 144 & up to 190 \\
\hline Triglycerides (mg/dL) & 90 & up to 150 \\
\hline $\mathrm{C3c}(\mathrm{g} / \mathrm{L})$ & 1,21 & $0,9-1,8$ \\
\hline C4 (g/L) & 0,13 & $0,1-0,4$ \\
\hline Folic acid (ng/mL) & 6,7 & >12 [deficiency: < 7] \\
\hline Vitamin D 25-OH (nmol/L) & 21 & 51-250 [deficiency/shortage: $<25]$ \\
\hline Total protein (g/L) & 61,9 & $66-83$ \\
\hline$\gamma$-Globulin (g/L) & 8,7 & $6.4-16.2$ \\
\hline $\operatorname{lgA} g / L$ & 0,97 & $0,7-4$ \\
\hline $\operatorname{lgG} g / L$ & 9,45 & $7-16$ \\
\hline $\operatorname{lgMg} / \mathrm{L}$ & 0,25 & $0,4-2,3$ \\
\hline WBC (x10^9/L) & 13.94 & $4-10$ \\
\hline CEA $(\mu \mathrm{g} / \mathrm{L})$ & 0,7 & $0-4$ \\
\hline CA 19-9 (KU/L) & 5 & $<31$ \\
\hline Vitamin B12 (pmol/L) & 527 & $156-672$ \\
\hline
\end{tabular}

$\gamma \mathrm{GT}=\gamma$-Glutamyltransferase; $\mathrm{ALP}=$ Alkaline phosphatase; $\mathrm{ALT}=$ Alanine transaminase; $\mathrm{AST}=$ Aspartate transaminase $\mathrm{CRP}=\mathrm{C}$-Reactive protein; $\mathrm{WBC}=$ White blood count

Tests for occult blood, parasites in the stool, $\mathrm{HBsAg}$, and anti-HCV were negative.

A CT-scan of the abdomen showed no alterations of the pancreas (Baltazar score ' $A$ '), acalculous gallbladder, oval mesenteric lymph nodes with a diameter of less than $1 \mathrm{~cm}$, and vascular calcifications of the pancreatic-lienale artery (Figure 1). 


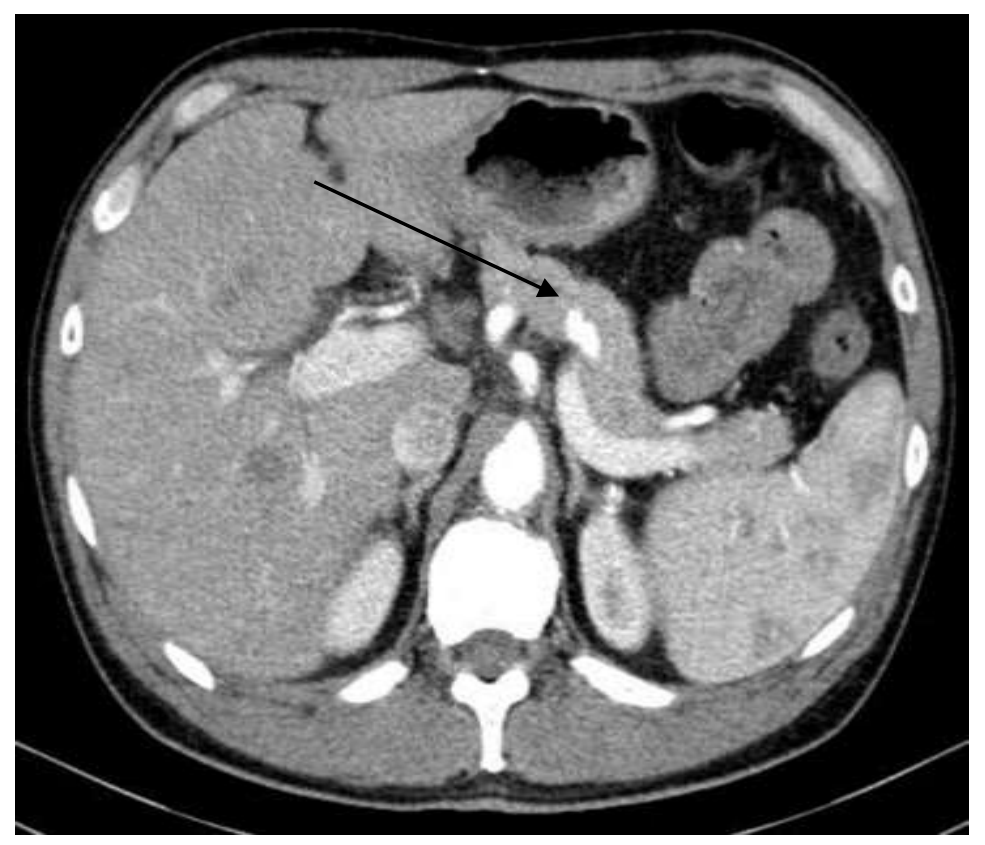

Figure 1 CT abdomen (January 2015; first observation).

The patient was treated with an infusion of pantoprazole and glucose solution. The pancreatic enzymes were normalized on the sixth day. He was discharged with a prescription for oral pantoprazole, vitamin $D$, and folic acid. Losartan was not prescribed.

We did not determine the etiology of acute pancreatitis. Therefore, we formulated the diagnosis of acute pancreatitis (idiopathic?) also a quick resolution [15]. The diagnosis of pancreatitis in subject with hypereosinophilia and eosinophilic pancreatitis was left open [13].

During the follow-up, 35 months after our first observation, the patient remained asymptomatic without steroid therapy. However, mild eosinophilia persisted with normal levels of total IgE, amylase, lipase, C3, and C4 (Table 3).

Table 3 Results of laboratory tests (during the asymptomatic follow-up: 35 months).

\begin{tabular}{|c|c|c|}
\hline Parameters & Detected Levels & Normal Range \\
\hline Eosinophils $\left(\times 10^{\wedge} 3 / \mu \mathrm{L}\right)$ & 0.67 (9.5\% of leukocytes) & $0.04-0.65$ \\
\hline IgE total & 4,9 & $<100$ \\
\hline Amylase total (UI/L) & 69 & $10-100$ \\
\hline Lipase (UI/L) & 32 & $12-55$ \\
\hline $\mathrm{C} 3$ (mg/dL) & 100 & $90-120$ \\
\hline $\mathrm{C} 4(\mathrm{mg} / \mathrm{dL})$ & 12 & $10-40$ \\
\hline $\operatorname{lgM}(\mathrm{mg} / \mathrm{dL})$ & 22 & $65-210$ \\
\hline $\lg \mathrm{A}(\mathrm{mg} / \mathrm{dL})$ & 114 & $114-400$ \\
\hline $\operatorname{lgG}(\mathrm{mg} / \mathrm{dL})$ & 844 & $700-1440$ \\
\hline $\operatorname{lgG}-1$ (mg/dL) & $646(76.5 \%$ of total IgG) & $58-74 \%$ of total lgG \\
\hline $\operatorname{lgG}-2$ (mg/dL) & $167(19.7 \%$ of total IgG) & $15-30 \%$ of total IgG \\
\hline $\operatorname{lgG}-3$ (mg/dL) & 31 (3.6\% of total IgG) & $3.5-11,1 \%$ of total IgG \\
\hline $\operatorname{lgG}-4(\mathrm{mg} / \mathrm{dL})$ & $0.39(0 \%$ of total IgG) & $1.6-6,8 \%$ of total IgG \\
\hline
\end{tabular}


During the 35th month, the patient had an episode of abdominal pain that was not associated with an increase in pancreatic indices. The eosinophil count was $2.47 \times 10^{\wedge} 3 / \mu \mathrm{L}(16.4 \%)$ and the abdominal ultrasound was normal.

In December 2017, the patient complained of food poisoning-led gastroenteritis. Tests revealed normal total IgE levels (4.9 kUI/L: nv <100), total cholesterol was $196 \mathrm{mg} / \mathrm{dL}$, and triglyceride content was $136 \mathrm{mg} / \mathrm{dL}$. He was treated with pantoprazole, losartan + hydrochlorothiazide, and magnesium hydroxide + aluminum hydroxide. In January 2018, he was hospitalized for nausea and intense abdominal pain with diarrhea in the absence of fever (Table 4). His BMI was $27.25 \mathrm{~kg} / \mathrm{m}^{2}$.

Table 4 Results of laboratory tests (January 2018: after a 36-month follow-up).

\begin{tabular}{|c|c|c|}
\hline Parameters & Detected Levels & Normal Range \\
\hline WBC $\left(\times 10^{\wedge} 3 / \mu \mathrm{L}\right)$ & 16.96 & $4.0-11.0$ \\
\hline Eosinophils $\left(\times 10^{\wedge} 3 / \mu \mathrm{L}\right)$ & 7.70 (45.4\% of leukocytes) & $0.04-0.65$ \\
\hline $\mathrm{ESR}(\mathrm{mm} / \mathrm{h})$ & 3 & $1-10$ \\
\hline $\mathrm{CRP}(\mathrm{mg} / \mathrm{L})$ & 0,86 & $<5$ \\
\hline Total amylase (IU/L) & 88 & $10-100$ \\
\hline Pancreatic amylase (IU/L) & 72 & $8-53$ \\
\hline Lipase (IU/L) & 102 & $12-55$ \\
\hline AST (UI/L) & 16 & $5-40$ \\
\hline ALT (UI/L) & 13 & $5-40$ \\
\hline ALP (UI/L) & 54 & $40-129$ \\
\hline yGT (UI/L) & 11 & $8-61$ \\
\hline Total cholesterol (mg/dL) & 182 & $<200$ \\
\hline Triglycerides (mg/dL) & 135 & $40-150$ \\
\hline Folic acid $(\mathrm{ng} / \mathrm{mL})$ & 3.0 & $3.1-17.5$ \\
\hline Vitamin $\mathrm{D}(25-\mathrm{OH})(\mathrm{ng} / \mathrm{mL})$ & 19 & $31-100$ \\
\hline Vitamin B12 (pg/mL) & 507 & $211-911$ \\
\hline Total protein (g/L) & 61.5 & $66-81$ \\
\hline$\gamma$-Globulin (g/L) & 7.6 & $8.0-13.5$ \\
\hline $\operatorname{lgM}(\mathrm{mg} / \mathrm{dL})$ & $21 \rightarrow 39$ & $65-210$ \\
\hline $\operatorname{lgA}(\mathrm{mg} / \mathrm{dL})$ & $83 \rightarrow 123$ & $140-400$ \\
\hline $\operatorname{lgG}(\mathrm{mg} / \mathrm{dL})$ & $774 \rightarrow 1170$ & $740-1440$ \\
\hline IgE total (kUI/L) & 153 & $<100$ \\
\hline $\mathrm{C} 3(\mathrm{mg} / \mathrm{dL})$ & 100 & $90-220$ \\
\hline $\mathrm{C} 4(\mathrm{mg} / \mathrm{dL})$ & 12 & $10-40$ \\
\hline Serum $\beta 2$-microglobulin (mg/L) & 2.0 & $1.1-2.5$ \\
\hline ASMA & absent & \\
\hline $\operatorname{lgG1}(\mathrm{mg} / \mathrm{dL})$ & 741 & $58-74 \%$ of total IgG \\
\hline $\operatorname{lgG2}(\mathrm{mg} / \mathrm{dL})$ & 232 & $15-30 \%$ of total IgG \\
\hline $\operatorname{lgG3}(\mathrm{mg} / \mathrm{dL})$ & 31 & $3,5-11,1 \%$ of total IgG \\
\hline IgG4 (mg/dL) & 2 & $1,6-6,8 \%$ of total IgG \\
\hline
\end{tabular}

$\gamma \mathrm{GT}=\gamma$-Glutamyltransferase; $\mathrm{ALP}=$ Alkaline phosphatase $; \mathrm{ALT}=$ Alanine transaminase $\mathrm{ASMA}=$ Anti-Smooth Muscle Antibodies; AST = Aspartate transaminase; CRP = C-Reactive protein; ESR = Erythrocyte sedimentation rate; $\mathrm{WBC}=$ White blood count 
Immunophenotyping by flow cytometry was performed on peripheral blood and revealed no phenotypic alterations of B/T-lymphocytes. The stool examination revealed that ova and parasites were absent. The level of elastase in the feces was $>500 \mu \mathrm{g} / \mathrm{g}$ ( $\mathrm{nv}>200)$. Stool cultures for Shigella, Salmonella, Campylobacter, Clostridium difficile antigen, Escherichia coli 0157:H7, Giardia, Strongyloides, Toxocara, and Cryptosporidium were negative. The fecal tests for Rotavirus and Adenovirus, the anti-Entamoeba Histolytic Ab, anti-Strongyloides stercoralis IgG, and anti-Yersinia enterocolitica Ab were all negative. Tests for Clostridium difficile toxin, such as serology for EBV and toxoplasma, were negative. CMV test suggested a possible remote infection, while Quantiferon was negative. The abdominal CT (Figure 2) showed perihepatic-splenic effusion; diffuse hypodense edematous thickening of the colon, particularly the right and transversus; a similar thickening of the last loops of the small intestine; normal liver, spleen, adrenal gland, and pancreas; and some cysts on the left kidney.

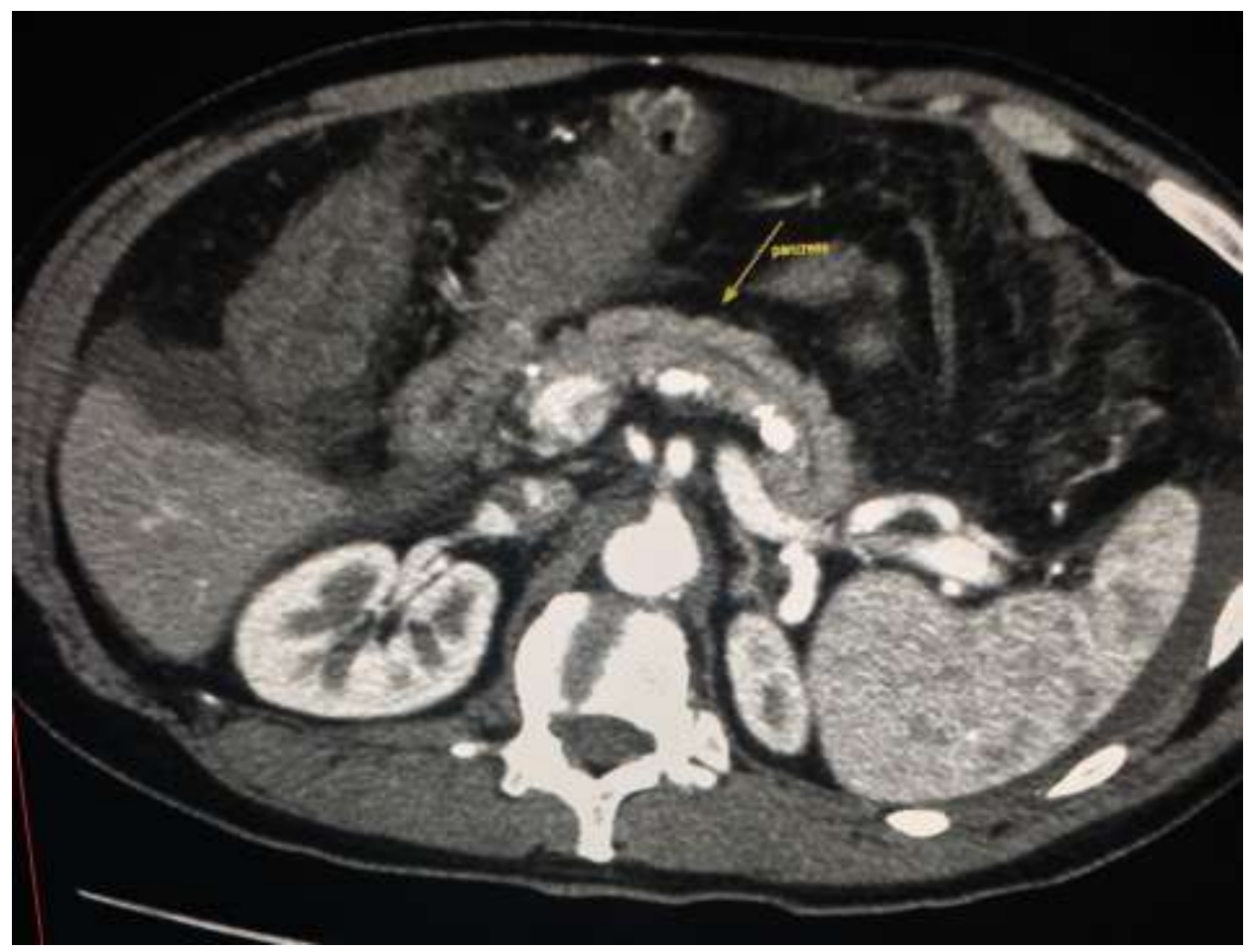

Figure 2 CT of the abdomen (February 2018).

The electrocardiogram revealed sinus rhythm and left axial deviation. Echocardiogram showed $60 \% \mathrm{FE}$, false apical tendons, and slight aortic insufficiency.

An empirical antibiotic regimen with oral metronidazole and intravenous tigecycline was prescribed.

Colonoscopy carried out after this course of therapy showed regular transit up to the cecal fundus and last centimeter of the distal ileum, which appeared to be patent and plastic, and covered with undamaged mucosa (Figure 3). 


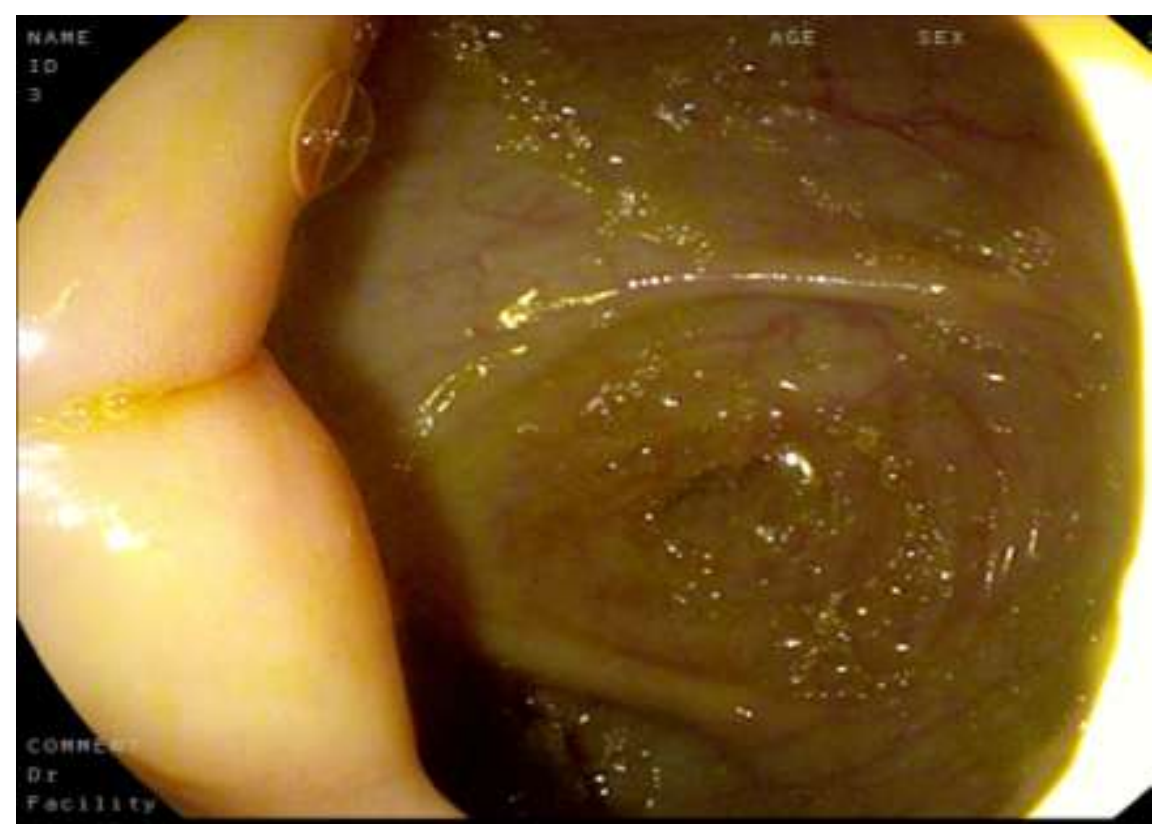

Figure 3 Colonoscopy (February 2018): mucosa macroscopically undamaged.

Random biopsies showed hyperplastic aspects of the glands in the right colon, mild edema in the lamina propria, lymphoid aggregates, inflammatory lymphoplasmacellular infiltrate, and granulocytic eosinophils (high-power field [HPF] eosinophil count: 15-20 per field). Similar findings were observed on the left colon, except that the eosinophils were rare (Figure 4 and Figure 5 colonic biopsies: H\&E staining).

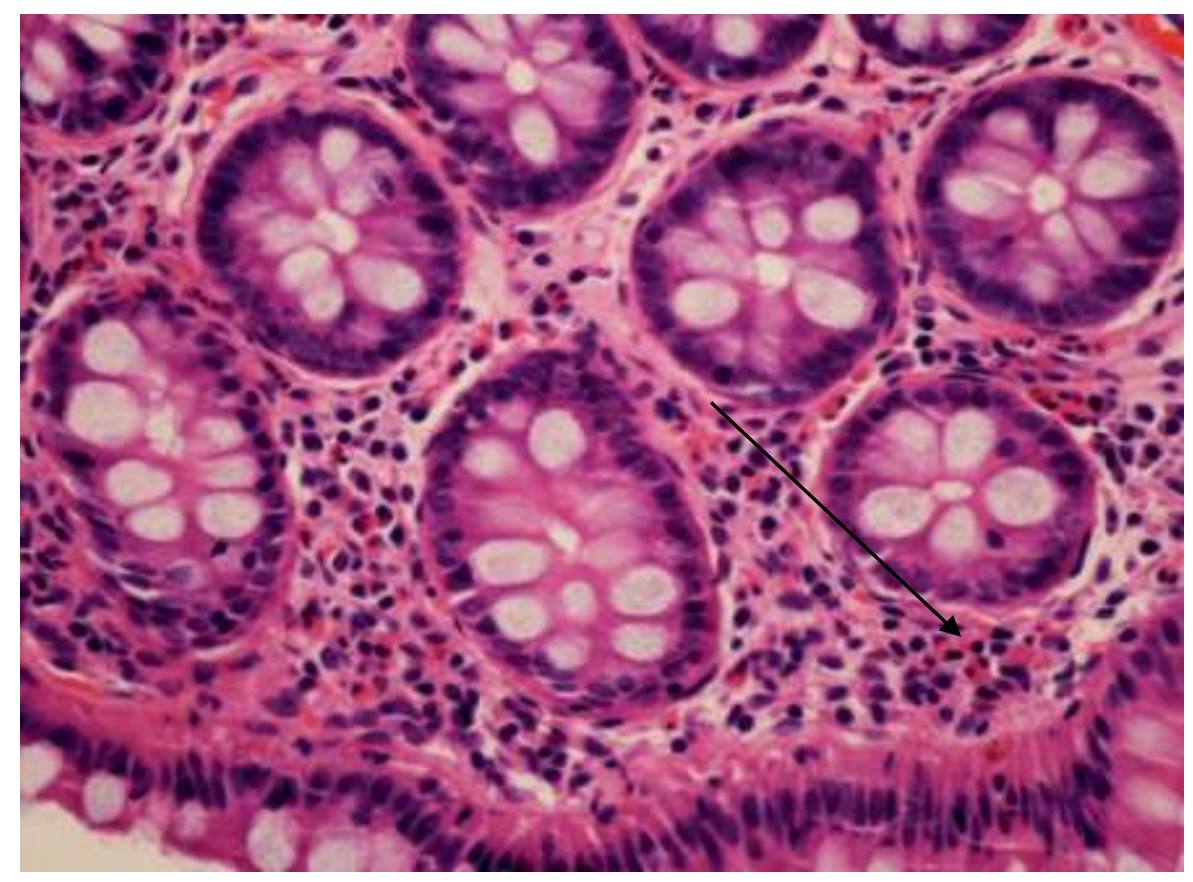

Figure 4 Biopsy on the right colon (February 2018). Hematoxylin-eosin staining, original magnification $\times 40$ : numerous eosinophilic granulocytes close to the glandular crypts are observed. 


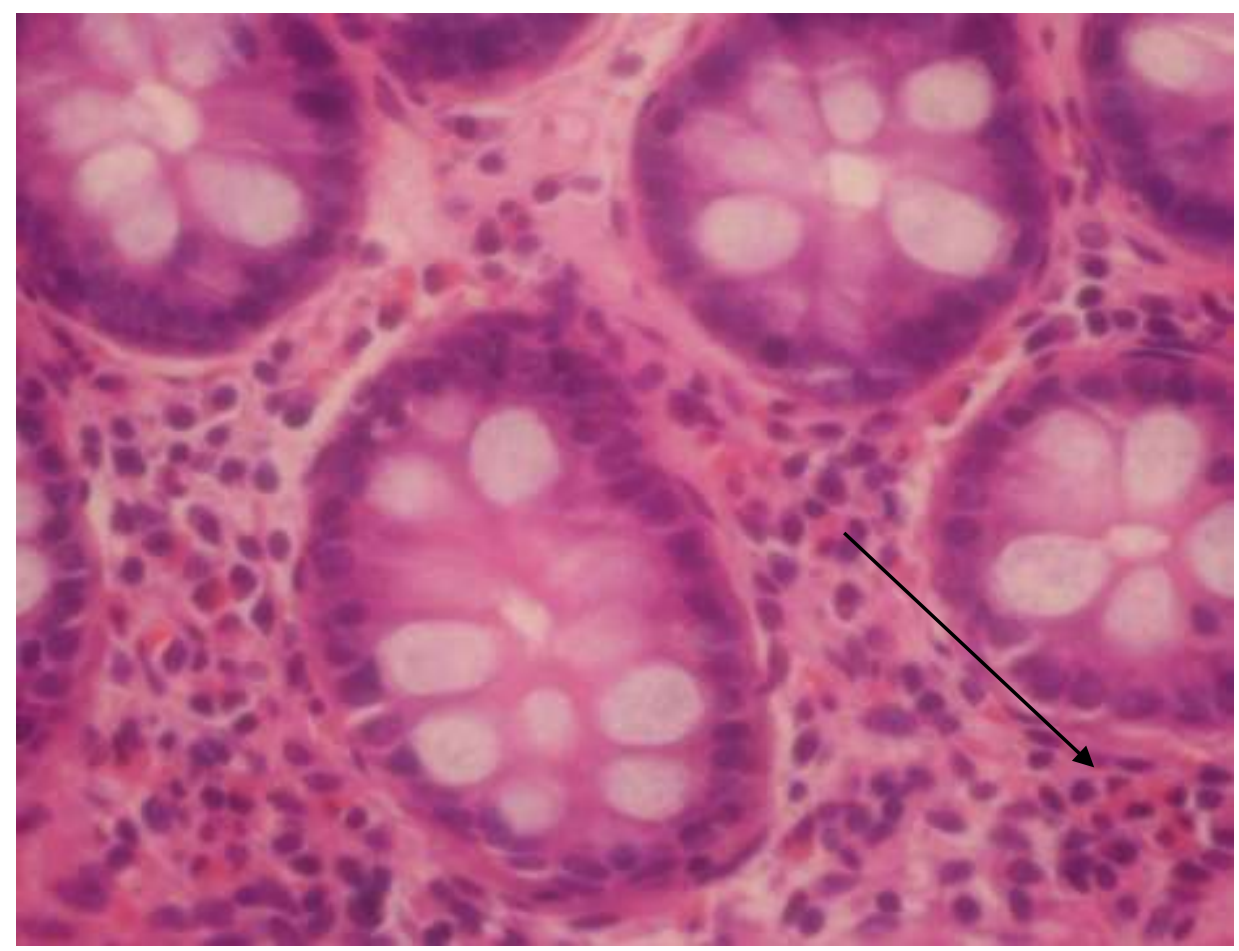

Figure 5 Biopsy on the right colon (February 2018). Hematoxylin-eosin staining, original magnification $\times 60$ : numerous eosinophilic granulocytes close to the glandular crypts are observed.

An esophagogastroduodenoscopy was also performed, which revealed a macroscopically normal pattern. Two random biopsies of the esophagus highlighted 2-3 eosinophils/HPF per sample, while no morphological findings related to eosinophilic esophagitis were observed. Gastric mucosa showed mild, inactive chronic gastritis, while the histochemical test (Giemsa) for Helicobacter pylori was negative. The patient was discharged after 20 days with a tentative diagnosis of eosinophilic mucosal segmental (right) colitis (EoC), and was prescribed budesonide ( 9 $\mathrm{mg} /$ day) for two months, then $6 \mathrm{mg} /$ day for a month, and subsequently $3 \mathrm{mg} /$ day for another 2-3 months. After a few months, the patient suspended cortisone therapy on his own accord.

During the last 22 months of follow-up, the patient was asymptomatic. The complete blood count without budesonide therapy showed WBC $\left(7.15 \times 10^{\wedge} 3 / \mu \mathrm{L}\right)$, eosinophil count between $0.54 \times 10^{\wedge} 3 / \mu \mathrm{L}(7.5 \%)$ and $1.18 \times 10^{\wedge} 3 / \mu \mathrm{L}(19 \%)$, normal level of serum total IgE $(6.0 \mathrm{kUI} / \mathrm{L}$ [1.5100]); IgM: $26 \mathrm{mg} / \mathrm{dL}$ (65-210), IgA: $112 \mathrm{mg} / \mathrm{dL}$ (140-400), IgG: $783 \mathrm{mg} / \mathrm{dL}$ (740-1440), serum tryptase: $5.1 \mu \mathrm{g} / \mathrm{L}$ (0.0-12.0); ASCA (Anti-Saccharomyces cerevisiae antibodies): IgA: $0 \mathrm{UI} / \mathrm{mL}$ (010), IgG $1 \mathrm{UI} / \mathrm{mL}$ (0-10); Immunoglobulin-A anti-tissue transglutaminase (IgA anti-tTG): $2 \mathrm{UA} / \mathrm{mL}$ (<10 negative); ANCA Ab (antineutrophil cytoplasmic antibodies): MPO-ANCA and PR3-ANCA absent; ferritine: $702 \mathrm{ng} / \mathrm{mL}$ (30-400); folic acid: $4.4 \mathrm{ng} / \mathrm{mL}$ (3.1-17.5); and vitamin D 25-OH: 25.1 $\mathrm{ng} / \mathrm{mL}$ (insufficiency: $10-30 \mathrm{ng} / \mathrm{mL}$ ).

\section{Discussion}

We have described the evolution of an intriguing clinical case of a man with persistent hypereosinophilia, who had presented repeated episodes of abdominal colic over the course of nearly 22 years, an episode of self-limited pancreatitis, and at least two episodes of significant 
enterocolitis.

The acute abdominal episodes were always associated with a marked increase in eosinophils but without an increase in IgE.

We specifically ruled out the possibility of type-1 autoimmune pancreatitis (IgG-4 dosage typically less than $135 \mathrm{mg} / \mathrm{dL}$ ) and iatrogenic pancreatitis due to losartan, as the drug was continued without consequences [12]. A new episode of acute abdominal colic reoccurred after 18 years from the first, in the absence of cortisone therapy. No malignant transformation was observed during this long observation period.

In the differential diagnosis of possible eosinophilic colitis, we ruled out other causes of tissue eosinophilia that may rarely involve the colonic mucosa, such as eosinophilic granulomatosis with vasculitis (EGPA: Churg-Strauss syndrome), diffuse fasciitis with eosinophilia (EFE), eosinophiliamyalgia syndrome, idiopathic eosinophilic myositis, IgG4-related disease, mastocytic colitis (normal serum tryptase and vitamin B12), connective tissue diseases (e.g., systemic sclerosis), colonic spirochetosis, drug-induced colitis, and inflammatory bowel diseases (with excess eosinophils in mucosal biopsies) (Crohn's disease) [16].

We particularly excluded quiescent ulcerative colitis, which may be associated with an increase in the activated colonic eosinophils, as we found neither distorted mucosal architecture nor the prominence of dense mixed inflammatory infiltrates [16-18].

Regarding drug-induced colitis, there was no history of the intake of potentially colon-damaging drugs, such as NSAIDs, mycophenolate, tacrolimus, cyclosporine, clozapine, carbamazepine, antiplatelet drugs, rifampicin, gold, naproxen, estrogen, and progesterone.

Therefore, we excluded all the known causes of increased mucosal colon eosinophils.

The classification of the system involvement of eosinophilic gastroenteritis (EoGE) is based on the extent of eosinophilic inflammation. Three different patterns have been described: mucosal (70\%), muscular (20\%), and serosal (10\%), where multiple layers are frequently involved [19]. In our case, only mucosal involvement was observed. Owing to the lack of DNA sequencing tools, it was not possible to detect the gene sequence of FIP1-like 1/platelet-derived growth factor receptor alpha fusion (F/P). This mutation is the most common molecular abnormality detected in clonal idiopathic hyper-eosinophilic syndrome (IHES), called F/P-positive chronic eosinophilic leukemia (CEL) [2]. The evaluation of serum tryptase, in addition to excluding mastocytosis, was used as a surrogate marker for F/P-positive disease. We did not measure the eosinophilic cationic protein (ECP), a serological marker of eosinophil activation, as the patient had asthma only during his youth.

Regarding eosinophilic pancreatitis, from the year 1990 to September 2019, about 40 cases have been reported in PubMed (MEDLINE), and more specifically in the following countries: USA [20-27], Turkey [28, 29], China [30, 31], Korea [32, 33], France [34-37], India [38, 39], Italy [12] Japan [40-42], Denmark [24], Great Britain [43], Brazil [44], and Tunisia [45].

A recent review classified 45 reports into cases with eosinophilic gastroenteritis that had developed pancreatitis (n.20), cases with isolated eosinophilic pancreatitis (n.20), and 5 patients with hypereosinophilic syndrome involving the pancreas: no significant differences were found regarding the clinical, laboratory and imaging characteristics between the three groups, even if subjects with eosinophilic pancreatitis underwent surgery to rule out a potential malignant lesion [14]. 


\section{Conclusions}

In the diagnostic process, we followed the indications provided by Turner et al. [17], who proposed an algorithm for the diagnosis of either colonic eosinophilia or eosinophilic colitis. As the number of eosinophils/HPF in the right colon did not reach the minimum number reported in the algorithm in our case, we excluded the diagnosis of eosinophilic colitis.

The presence of colonic eosinophilia in adults is indicated by the finding of $>50$ eosinophils/HPF in the right colon, $>35$ eosinophils/HPF in the transverse colon, and $>25$ eosinophils/HPF in the left colon [17]. To confirm the normality of eosinophil levels, studies were carried out on children, that showed a gradual decrease in the number of eosinophils in the lamina propria, from the cecum to the descending colon [46-48].

In a recent large multicenter retrospective study on 108 cases (children and adults) in the US, eosinophilic colitis was diagnosed as a mean peak colonic eosinophilic count of 60 eosinophils/HPF, with a range of 45-85, as recorded in 80 patients that were subjected to biopsies. The presenting symptoms of EC were abdominal pain (60\%), diarrhea (52\%), nausea and/or vomiting (38\%), bloody stools (24\%), constipation (17\%), early satiety or loss of appetite, dysphagia (8\%), regurgitation, bloating, food aversion/refusal, nocturnal awakening due to pain, irritability and/or crying (6\%), and chest pain (2\%). Only $1 \%$ of the patients showed no symptoms [49].

Therefore, it is worth noting that the criteria for the histopathological diagnosis of eosinophilic colitis remains undefined, as there is a marked difference between observers [50].

Unlike the primary colonic eosinophilia (PCE), the presence of signs and symptoms associated with hypereosinophilia (HE) facilitates the final diagnosis of non-infectious acute colitis associated with either idiopathic hypereosinophilic syndrome (IHES) or hypereosinophilia of unknown significance (HEUS) $[9,10,17,51]$, that are otherwise difficult to classify.

Regarding EoC, it is an exceptionally rare entity, with a prevalence of $2-3 / 100,000$ persons $(0.0003 \%)$ in the USA, but has been diagnosed in $0.1 \%$ of the biopsies of patients that had undergone colonoscopy for diarrhea [7,52]. In the list of rare diseases of ORPHANET, eosinophilic colitis is categorized as ORPHA $n^{\circ}$ 402035, with 196 reported cases (as of January 2019), prevalence $<1 / 1,000,000$, and age of onset as during childhood or adulthood [53, 54]. ICD-10-CM diagnosis code is K52.82. Two US studies have recently reported an overestimation of the prevalence of EC in the pediatric population with a single billing code $[55,56]$.

Eosinophilic colitis is primarily a self-limiting disease. Although the natural history of EoC is not well-defined, in adults, it tends to become chronic with periods of exacerbation and remission.

When required, drug treatment follows the standard medication for other inflammatory bowel diseases, but older individuals may require more aggressive management, as IgE-associated triggers, in contrast to other EGIDs, are rarely identified [11, 57]. In relapses, long-term low-dose corticosteroids (namely oral prednisone) may be required. Budesonide, in controlled ileal-release capsule formulation, has been reported to induce and maintain remission, particularly when the right colon and ileum are affected $[11,58]$.

Other successful therapies in eosinophilic enteritis include sodium cromolyn, montelukast, ketotifen, and suplatast tosilate. Immunomodulatory agents (e.g., azathioprine or 6mercaptopurine) can be used in severe, refractory, or steroid-dependent EoC.

Emerging therapies focusing on humanized monoclonal antibodies (e.g., anti-IL -5 and anti-TNF agents) that target inflammatory mediators, are under evaluation [10, 51] 
The most recent reviews on eosinophilic colitis were published in 2019 by Australian [52] and Italian [59] authors.

This enigmatic clinical case leaves at least two practical questions open:

1. If long-term low-dose oral corticosteroids are required in case of relapses, how long should steroid therapy (with budesonide or prednisone) be used to prevent further recurrences?

2. Alternatively, which steroid-sparing agent should be used and for what duration?

\section{Key Points}

- Hypereosinophilia is defined by an absolute eosinophil count greater than $1,500 \mathrm{cells} / \mathrm{mm}^{3}$ for more than one month, and evidence of eosinophilia-associated organ impairment

- Eosinophilic colitis is an exceptionally rare condition with few described cases in the literature.

- It represents the least frequent manifestation of the wide spectrum of eosinophilic gastrointestinal disorders.

- It is almost always associated with peripheral hypereosinophilia; the clinical manifestations are related to the level of infiltration of the intestinal wall.

- In the presence of persistent peripheral hypereosinophilia, the investigations leading to a certain diagnosis are numerous and range from the search for allergies to the dosage of IgE, and up to determination of specific genetic mutations.

- Descriptions of pancreatitis associated with eosinophilic gastroenteritis are rare.

- Eosinophilic pancreatitis is considered to be a variant of autoimmune pancreatitis. In the differential diagnosis, a criterion of distinction is given by the IgG-4 blood dosage.

- Drug treatment follows the standard medication for other inflammatory bowel diseases, but older individuals may require more aggressive management.

\section{Abbreviations}

EGIDs: Eosinophilic Gastrointestinal Disorders; EGE: Eosinophilic GI disease with peripheral eosinophilia; EoE: Eosinophilic Esophagitis; EoG: Eosinophilic Gastritis; EoGE: Eosinophilic Gastroenteritis; EoC: Eosinophilic Colitis; EE: Eosinophilic Enteritis; EP: Eosinophilic Pancreatitis; PCE: Primary Colonic Eosinophilia; HE: Hypereosinophilia; FE: Familial Eosinophilia; CEL: Chronic Eosinophilic Leukemia; HES: Hypereosinophilic syndrome; HEUS: Hypereosinophilic syndrome of unknown significance; IHES: Idiopathic hypereosinophilic syndrome; EFE: Eosinophilic fasciitis with peripheral eosinophilia; FIP1L1: Fip1-like1; PDGFRA: Platelet-derived growth factor receptor $\alpha$; PDGFRB: Platelet-derived growth factor receptor $\beta$; EGPA: Eosinophilic granulomatosis with polyangiitis; HPF: high-power field (eosinophils count); AEC: absolute eosinophil count.

\section{Author Contributions}

M.T. provided the clinical data and has written the text, B.M. and I.S. provided clinical data, S.B. has provided iconography and pathological comments.

\section{Competing Interests}

The authors have declared that no competing interests exist. 


\section{References}

1. Simon HU, Rothenberg ME, Bochner BS, Weller PF, Wardlaw AJ, Wechsler ME, et al. Refining the definition of hypereosinophilic syndrome. J Allergy Clin Immunol Pract. 2010; 126: 45-49.

2. Valent $\mathrm{P}$, Klion AD, Horny HP, Roufosse F, Gotlib J, Weller PF, et al. Contemporary consensus proposal on criteria and classification of eosinophilic disorders and related syndromes. J Allergy Clin Immunol Pract. 2012; 130: 607-612. e609.

3. Williams KW, Ware J, Abiodun A, Holland-Thomas NC, Khoury P, Klion AD. Hypereosinophilia in children and adults: A retrospective comparison. J Allergy Clin Immunol Pract. 2016; 4: $941-$ 947. e941.

4. Kahn JE, Groh M, Lefevre G. (A critical appraisal of) classification of hypereosinophilic disorders. Front Med. 2017; 4: 216.

5. Leru PM. Eosinophilic disorders: Evaluation of current classification and diagnostic criteria, proposal of a practical diagnostic algorithm. Clin Transl Allergy. 2019; 9: 36.

6. Zhang M, Li Y. Eosinophilic gastroenteritis: A state-of-the-art review. J Gastroenterol Hepatol. 2017; 32: 64-72.

7. Mansoor E, Saleh MA, Cooper GS. Prevalence of eosinophilic gastroenteritis and colitis in a population-based study, from 2012 to 2017. Clin Gastroenterol Hepatol. 2017; 15: 1733-1741.

8. Sunkara T, Rawla P, Yarlagadda KS, Gaduputi V. Eosinophilic gastroenteritis: Diagnosis and clinical perspectives. Clin Exp Gastroenterol. 2019; 12: 239-253.

9. Rothenberg ME. Eosinophilic gastrointestinal disorders (EGID). J Allergy Clin Immunol Pract. 2004; 113: 11-28; quiz 29.

10. Diaz Del Arco C, Taxonera C, Olivares D, Fernandez Acenero MJ. Eosinophilic colitis: Case series and literature review. Pathol Res Pract. 2018; 214: 100-104.

11. Alfadda AA, Shaffer EA, Urbanski SJ, Storr MA. Eosinophilic colitis is a sporadic self-limited disease of middle-aged people: A population-based study. Colorectal Dis. 2014; 16: 123-129.

12. Turrin M. Rare causes of acute pancreatitis: Drugs, eosinophilia, and autoimmunity. OBM Hepatol Gastroenterol. 2019; 3: 20.

13. Guler S, Cimen S, MacDonald F, Hurton S, Molinari M. Eosinophilic pancreatitis. In: Rare diseases. Hauppauge, NY; Nova Science Publishers, Inc; 2014.

14. Pinte L, Băicuș C. Eosinophilic pancreatitis versus pancreatitis associated with eosinophilic gastroenteritis-a systematic review regarding clinical features and diagnosis. Rom J Intern Med. 2019; DOI: 10.2478/rjim-2019-0012.

15. Turrin M, Martinelli S. Acute pancreatitis at quick resolution: Merit of Eosinophils? Intern Emerg Med. 2016; 10: S107-S108.

16. Lwin T, Melton SD, Genta RM. Eosinophilic gastritis: Histopathological characterization and quantification of the normal gastric eosinophil content. Mod Pathol. 2011; 24: 556-563.

17. Turner KO, Sinkre RA, Neumann WL, Genta RM. Primary colonic eosinophilia and eosinophilic colitis in adults. Am J Surg Pathol. 2017; 41: 225-233.

18. Collins MH, Capocelli K, Yang GY. Eosinophilic gastrointestinal disorders pathology. Front Med. 2018; 4: 231.

19. Klein NC, Hargrove RL, Sleisenger MH, Jeffries GH. Eosinophilic gastroenteritis. Medicine. 1970; 49: 299-320. 
20. Polyak S, Smith TA, Mertz H. Eosinophilic gastroenteritis causing pancreatitis and pancreaticobiliary ductal dilation. Dig Dis Sci. 2002; 47: 1091-1095.

21. Abraham SC, Leach S, Yeo CJ, Cameron JL, Murakata LA, Boitnott JK, et al. Eosinophilic pancreatitis and increased eosinophils in the pancreas. Am J Surg Pathol. 2003; 27: 334-342.

22. Stevens T, Mackey R, Falk GW, Bennett A, Henderson JM. Eosinophilic pancreatitis presenting as a pancreatic mass with obstructive jaundice. Gastrointest Endosc. 2006; 63: 525-527.

23. Kakodkar S, Omar H, Cabrera J, Chi K. Eosinophilic pancreatitis diagnosed with endoscopic ultrasound. ACG Case Rep J. 2015; 2: 239-241.

24. Lyngbaek S, Adamsen S, Aru A, Bergenfeldt M. Recurrent acute pancreatitis due to eosinophilic gastroenteritis. Case report and literature review. JOP. 2006; 7: 211-217.

25. Tse KY, Christiansen SC. Eosinophilic gastroenteritis due to egg allergy presenting as acute pancreatitis. Allergy Rhinol. 2015; 6: 80-81.

26. Reppucci J, Chang M, Hughes S, Liu X. Eosinophilic pancreatitis: A rare cause of recurrent acute pancreatitis. Case Rep Gastroenterol. 2017; 11: 120-126.

27. Abdalgani M, Irani AM. Hypereosinophilic syndrome presenting as acute pancreatitis. The J Allergy Clin Immunol Pract. 2013; 131: DOI: 10.1016/j.jaci.2012.12.1103.

28. Cay A, Imamoglu M, Cobanoglu U. Eosinophilic pancreatitis mimicking pancreatic neoplasia. Can J Gastroenterol. 2006; 20: 361-364.

29. Caglar E, Karismaz K, Dobrucali A. A case of eosinophilic gastroenteritis mimicking gastric lymphoma associated with pancreatitis due to duodenal involvement. Turk J Gastroenterol. 2012; 23: 585-589.

30. Tian L, Fu P, Dong X, Qi J, Zhu H. Eosinophilic pancreatitis: Three case reports and literature review. Mol Clin Oncol. 2016; 4: 559-562.

31. Zhu B, Bai $H$, Wu J. A patient with eosinophilic gastroenteritis presenting with acute pancreatitis. Zhonghua Er Ke Za Zhi. 2015; 53: 542-543.

32. Song JW, Kim MH, Seo WJ, Oh DR, Kim GD, Moon SH, et al. A case of eosinophilic pancreatitis. 2003; 42: 444-450.

33. Baek MS, Mok YM, Han WC, Kim YS. A patient with eosinophilic gastroenteritis presenting with acute pancreatitis and ascites. Gut Liver. 2014; 8: 224-227.

34. Barthet $M$, Hastier P, Buckley MJ, Bernard JP, Sastre B, Baroni JL, et al. Eosinophilic pancreatitis mimicking pancreatic neoplasia: EUS and ERCP findings - is non-surgical diagnosis possible? Pancreas. 1998; $17:$ 419-422.

35. Bastid C, Sahel J, Choux R, Payan MJ, Sarles H. Eosinophilic pancreatitis: Report of a case. Pancreas. 1990; 5: 104-107.

36. Bellaiche G, Fontaine H, Choudat L, Lusina D, Ley G, Slama JL. Pancreatic involvement, ascites and diarrhea in idiopathic hypereosinophilic syndrome. Gastroenterol Clin Biol. 1997; 21: 519522.

37. Roy-Peaud F, Paccalin M, Le Moal G, Landron C, Roblot P, Becq-Giraudon B. Eosinophilic pancreatitis. Presse Med. 2002; 31: 25.

38. Rakesh K, Banerjee R, Gupta R, Ramji C, Pradeep R, Rao GV, et al. Eosinophilic pancreatitis with pseudocyst. Indian J Gastroenterol. 2007; 26: 136-137.

39. Javid Bhat K, Bhat S, Dutt K, Gupta S, Jeelani Samoon H. Chronic diarrhea, eosinophilic ascites, acute pancreatitis and deep venous thrombosis: A case report. Caspian J Intern Med. 2014; 5: 182-185. 
40. Maeshima A, Murakami H, Sadakata H, Saitoh T, Matsushima T, Tamura J, et al. Eosinophilic gastroenteritis presenting with acute pancreatitis. J Med. 1997; 28: 265-272.

41. Suzuki S, Homma T, Kurokawa M, Matsukura S, Adachi M, Wakabayashi K, et al. Eosinophilic gastroenteritis due to cow's milk allergy presenting with acute pancreatitis. Int Arch Allergy Immunol. 2012; 158: 75-82.

42. Yasuoka Y, Yoshida A, Nakajyou T, Yamamoto T, Abe Y. A case report of eosinophilic pancreatitis presenting as inflammatory pancreatic tumor. Jpn J Gastroenterol surg. 2008; 41: 1953-1959.

43. Christopher $\mathrm{V}$, Thompson $\mathrm{MH}$, Hughes $\mathrm{S}$. Eosinophilic gastroenteritis mimicking pancreatic cancer. Postgrad Med J. 2002; 78: 498-499.

44. De Moura DTH, Rocha RSP, Jukemura J, Brunaldi VO, Guedes HG, Torrez FRA, et al. A rare nononcological pancreatic mass: Eosinophilic pancreatitis diagnosis through EUS-FNA. Endosc Int Open. 2019; 7: E151-E154.

45. Atig A, Ben Jazia E, Alaoua A, Khalifa M, Ghannouchi N, Braham A, et al. Acute pancreatitis due to idiopathic hypereosinophilic syndrome: A case report. Acta Endoscopica. 2011; 41: 26-28.

46. DeBrosse CW, Case JW, Putnam PE, Collins MH, Rothenberg ME. Quantity and distribution of eosinophils in the gastrointestinal tract of children. Pediatr Dev Pathol. 2006; 9: 210-218.

47. Saad AG. Normal quantity and distribution of mast cells and eosinophils in the pediatric colon. Pediatr Dev Pathol. 2011; 14: 294-300.

48. Silva J, Canao P, Espinheira MC, Trindade E, Carneiro F, Dias JA. Eosinophils in the gastrointestinal tract: How much is normal? Virchows Arch. 2018; 473: 313-320.

49. Pesek RD, Reed CC, Muir AB, Fulkerson PC, Menard-Katcher C, Falk GW, et al. Increasing rates of diagnosis, substantial co-occurrence, and variable treatment patterns of eosinophilic gastritis, gastroenteritis, and colitis based on 10-year data across a multicenter consortium. Am J Gastroenterol. 2019; 114: 984-994.

50. Hentschel F, Jansen AF, Gunther M, Pauli R, Luth S. Eosinophil counts in mucosal biopsies of the ileum and colon: Interobserver variance affects diagnostic accuracy. Patholog Res Int. 2018; 2018: 2638258.

51. Walker MM, Potter M, Talley NJ. Eosinophilic gastroenteritis and other eosinophilic gut diseases distal to the oesophagus. Lancet Gastroenterol Hepatol. 2018; 3: 271-280.

52. Walker MM, Potter MD, Talley NJ. Eosinophilic colitis and colonic eosinophilia. Curr Opin Gastroenterol. 2019; 35: 42-50.

53. I Quaderni di Orphanet. Elenco delle malattie rare e sinonimi: In ordine alfabetico. 2019. Avail able from: http://www.orpha.net/orphacom/cahiers/docs/IT/Elenco_malattie_rare_in_ordine _alfabetico.pdf.

54. Orphanet Report Series. Prevalence of rare diseases: Bibliographic data. 2019. Available from: https://www.orpha.net/orphacom/cahiers/docs/GB/Prevalence_of_rare_diseases_by_alphab etical_list.pdf.

55. Muir AB, Jensen E, Wechsler J, Menard-Katcher P, Falk G, Aceves S, et al. Overestimation of the prevalence of eosinophilic colitis with reliance on a single billing code. bioRxiv. 2018: 414557.

56. DiTommaso LA, Rosenberg CE, Eby MD, Tasco A, Collins MH, Lyles JL, et al. Prevalence of eosinophilic colitis and the diagnoses associated with colonic eosinophilia. J Allergy Clin Immunol Pract. 2019; 143: 1928-1930. e1923. 
57. Egan M, Furuta GT. Eosinophilic gastrointestinal diseases beyond eosinophilic esophagitis. Ann Allergy Asthma Immunol. 2018; 121: 162-167.

58. Siewert E, Lammert F, Koppitz P, Schmidt T, Matern S. Eosinophilic gastroenteritis with severe protein-losing enteropathy: Successful treatment with budesonide. Dig Liver Dis. 2006; 38: 55-59.

59. Impellizzeri G, Marasco G, Eusebi LH, Salfi N, Bazzoli F, Zagari RM. Eosinophilic colitis: A clinical review. Dig Liver Dis. 2019; 51: 769-773.

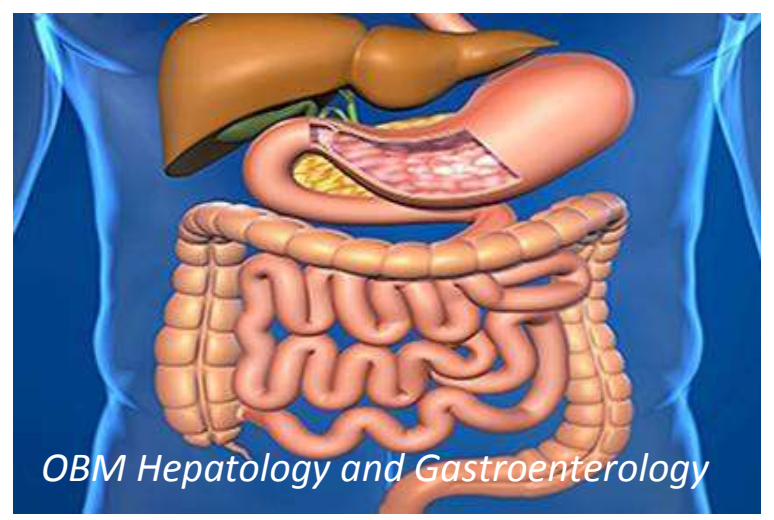

Enjoy OBM Hepatology and Gastroenterology by:

1. Submitting a manuscript

2. Joining in volunteer reviewer bank

3. Joining Editorial Board

4. Guest editing a special issue

For more details, please visit: http://www.lidsen.com/journals/hg 